Actualité internationale de la littérature critique sur l'art contemporain

23 | Printemps 2004

CRITIQUE D'ART 23

\title{
Eric Rondepierre
}

Muriel Caron

\section{OpenEdition \\ Journals}

Édition électronique

URL : http://journals.openedition.org/critiquedart/1756

DOI : $10.4000 /$ critiquedart. 1756

ISBN : 2265-9404

ISSN : 2265-9404

Éditeur

Groupement d'intérêt scientifique (GIS) Archives de la critique d'art

Édition imprimée

Date de publication : 1 avril 2004

ISBN : 1246-8258

ISSN : $1246-8258$

\section{Référence électronique}

Muriel Caron, «Eric Rondepierre », Critique d'art [En ligne], 23 | Printemps 2004, mis en ligne le 23 février 2012, consulté le 21 septembre 2020. URL : http://journals.openedition.org/critiquedart/1756 ; DOI : https://doi.org/10.4000/critiquedart.1756

Ce document a été généré automatiquement le 21 septembre 2020.

Archives de la critique d'art 


\title{
Eric Rondepierre
}

\author{
Muriel Caron
}

\section{RÉFÉRENCE}

Eric Rondepierre. Paris : Léo Scheer, 2003, (Photographies)

1 Comme il l'évoque dans son texte d'une grande lucidité, Eric Rondepierre est arrivé à la photographie après être passé de spectateur assidu de la cinémathèque à acteur évoluant entre performance, théâtre et danse, s'intéressant aux "micro-évènements, sensible à la dilatation du temps, à l'émergence de signes situés entre deux gestes, dans le ralenti extrême, la rupture subite". De l'image du corps au corps de l'image, « il me fallait ouvrir les yeux sur ma cécité. Sortir du spectacle par le noir.» Le cinéma, la capture du temps et de la réalité mobile sont ainsi au cœur de ses recherches photographiques travaillées par la tension: "Un art de la catastrophe et de la mort sans cesse évitée", écrit même Marie José Mondzain. Procédant par séries, des premiers Plans de coupes (1989) à Moins X (2003), il photographie des photogrammes ou des images arrêtées sur un écran de téléviseur pour «traquer les films dans leur intimité ", «travailler sur les limites » et dévoiler la réalité-pellicule, au bord de la disparition. Ainsi, les Précis de décomposition-Scène ou les Moires sont des agrandissements de photogrammes dévorés par l'acide. Les Plans de coupe, Inserts, Excédents sont des photos d'écrans noirs où s'impriment des sous-titres évocateurs (J'éteins? Non...), (KDK 1 appelle KDK 12. Est-ce que vous me recevez ?), (Rideau!) capturés dans des films aussi emblématiques que Le Voyeur, Shinning, Opening Night... Ou encore, dans la série des Annonces-vidéo, réalisée à partir de photogrammes extraits de bandes-annonces de films des années 1930-50, le texte, devenu illisible, barre le paysage ou les yeux et la bouche des personnages. "C'est que, note justement Marie José Mondzain, voir et montrer répondent à des désirs qui ont plus à voir avec la nuque des choses qu'avec leur face, avec un désir sans objet plutôt qu'avec le désir de savoir. » Les séries plus récentes, telles Suites, Dyptika ou Moins X, cadrées sur deux photogrammes, présentent des images divisées horizontalement qui invitent le regard à balancer entre deux espaces, à faire et défaire l'analogie. 
2 Parallèlement à ces "reprises de vues", E. Rondepierre réalise aussi des photographies comme La Muette à propos de laquelle Daniel Arasse écrit que « photographier ce serait voir en se défaisant de son propre regard », ou la belle série des Stances. Prises lors d'un voyage en train, ces photographies font défiler le paysage derrière les vitres, accompagnant le mouvement plutôt que de l'arrêter. C'est en ce sens qu'Alain Jouffroy, qualifiant le photographe de visionneur, écrit: «Presque tout ce que voit le voyageur $\mathrm{du}$ train, debout et immobile dans son couloir, lui échappe. Mais c'est dans cette échappée du réel que réside la fascination. [...] Le voyageur-photographe va tenter de fixer, précisément, ce qui disparaît. [...] L'appareil photographique a arrêté le processus de désagrégation du monde par la vitesse : une autre vision du temps en surgit. »

3 Heureusement que le texte de Pierre Guyotat et la qualité des reproductions offrent un regard anachronique dans cette mise en page impeccable et cet ensemble de contributions, certes prestigieuses, mais qui, pour le coup, figent un peu le mouvement. 